\title{
ACCOUNTABILITY NOS ATOS DA ADMINISTRAÇÃO PÚBLICA FEDERAL BRASILEIRA
}

\author{
ACCOUNTABILITY IN THE ACTS OF THE BRAZILIAN FEDERAL PUBLIC ADMINISTRATION
}

\author{
Bernardo Oliveira Buta \\ Aluno de doutorado em Administração Pública e Governo na Escola de Administração de Empresas de São Paulo - Fundação Getúlio \\ Vargas \\ São Paulo, SP, Brasil \\ Email: bernardo.buta@gmail.com \\ Marco Antonio Carvalho Teixeira \\ Professor do Programa de Pós-Graduação em Administração Pública e Governo da.Escola de Administração de Empresas de São \\ Paulo - Fundação Getúlio Vargas \\ São Paulo, SP, Brasil \\ Email: marco.teixeira@fgv.br \\ Vinicius Schurgelies \\ Coordenador do Curso Superior de Tecnologia em Gestão Pública - Universidade Metodista de São Paulo \\ São Paulo, SP, Brasil \\ Email: vschurgelies@gmail.com
}

\section{RESUMO}

O objetivo desse artigo é identificar a utilização do termo "accountability" pela Administração Pública Federal brasileira ao longo do tempo. A coleta de dados ocorreu mediante busca por atos administrativos no portal da Imprensa Nacional, utilizando a palavra-chave "accountability", e abrangeu todas as seções do Diário Oficial da União, de janeiro de 1990 a dezembro de 2017. Atos que tratam de accountability, mas não citam expressamente o termo não fizeram parte do escopo da pesquisa. Os 211 documentos encontrados foram avaliados por meio de análise de conteúdo diretiva. Observou-se uma crescente adoção do termo accountability na administração pública federal a partir de 2008, indicando um processo de significação desse termo. As definições superestimam a dimensão prestação de contas e negligenciam aspectos relativos a transparência. Observou-se também um descompasso entre os poderes na adoção desse termo, com maior concentração de atos no Poder Executivo e no Tribunal de Contas da União.

Palavras-chave: Accountability. Administração pública federal. Transparência. Prestação de contas. Responsabilização.

\section{ABSTRACT}

The purpose of this article is to identify the use of the term "accountability" by the Brazilian federal public administration over time. The data collection was held through search for administrative acts in the website of the National Press using the keyword "accountability", and covered all sections of the Official Diary of the Union from January 1990 to December 2017. Acts that deal with accountability but do not expressly cite the term are not part of the scope of the research. The 211 documents found were evaluated by means of directive content analysis. There was a growing adoption of the term accountability in federal public administration from 2008, indicating a process of meaning of that term. The definitions overestimate the accountability dimension and overlook aspects of transparency. There was also a mismatch between the powers in adopting this term, with a greater concentration of acts in the Executive Branch and in the Federal Court of Auditors.

Keywords: Accountability. Federal public administration. Transparency. Responsiveness. Provision of accounts. 


\section{INTRODUÇÃO}

Uma discussão constante acerca de accountability refere-se ao próprio significado deste termo na língua portuguesa. Tal questão foi inicialmente levantada em 1990, quando Ana Maria Campos constatou a ausência do conceito na administração pública brasileira, uma vez que a própria noção de coisa pública para burocratas e sociedade estaria distante (Campos, 1990). Quase vinte anos mais tarde, considerando a evolução institucional ocorrida neste período, Pinho e Sacramento (2009) concluíram que o conceito de accountability ainda estaria em processo de construção na sociedade brasileira, enquanto a cultura de accountability estava longe de se realizar (Pinho \& Sacramento, 2009).

Na última década, o termo accountability ganhou maior relevância. Contudo, ainda não encontrou consenso quanto a seu significado em português (Medeiros, Crantschaninov, \& Silva, 2013). Ressalta-se que, até mesmo na língua inglesa, seu significado é evasivo, seus limites são vagos e sua estrutura interna é confusa (Schedler, 1999), embora sua origem advenha de países anglo-saxões. Diante da deficiência de um significado claro, accountability vem sendo relacionada, na literatura acadêmica nacional, principalmente a responsabilização e prestação de contas, envolvendo também, em menor grau, transparência, sanções, controle, supervisão e responsabilidade (Medeiros, Crantschaninov, \& Silva, 2013).

Considerando a necessidade de estudos capazes de conferir melhor fundamentação para o tema e entender sua utilização no contexto brasileiro, alguns trabalhos concentraram-se em identificar aspectos de accountability na legislação federal (Abrucio \& Loureiro, 2004; Pinheiro, 2016; Sacramento \& Pinho, 2016). Contudo, os diplomas legais comumente analisados não adotam expressamente o termo accountability. Vale ressaltar que não é vedada a utilização de estrangeirismos em textos oficiais. Seu uso é aceitável, de forma consciente, nos casos em que as palavras exprimem realidades não contempladas na língua portuguesa (BRASIL., 2002).

Nesse sentido, torna-se relevante o questionamento se, de fato, o termo accountability não é citado nos documentos oficiais da administração pública no Brasil. Sendo citado, quais seriam os significados e contextos em que este termo é utilizado? Quais órgãos públicos estariam utilizando este termo? O objetivo deste trabalho é identificar a utilização do termo accountability pela administração pública federal brasileira ao longo do tempo. Destaca-se que atos legislativos ou jurisdicionais não foram incluídos no escopo da pesquisa.

Considerando a dificuldade em se traduzir para o português, espera-se que o termo accountability seja utilizado nos atos da administração pública federal, especialmente na última década, quando Medeiros et al. (2013) encontraram um aumento da relevância deste termo. Espera-se também que sua utilização se dê em grande parte por órgãos de controle, tais como o Tribunal de Contas da União - TCU - e o Ministério da Transparência e Controladoria-Geral da União - CGU -, uma vez que estes órgãos são os responsáveis pela tomada de contas dos agentes públicos, promoção da transparência no uso dos recursos públicos e responsabilização dos agentes malversadores desses recursos. Ademais, acredita-se que o termo accountability esteja associado a prestação de contas e responsabilização, assim como encontrado por Medeiros et al. (2013) nas definições adotadas na literatura sobre o tema. Por fim, acredita-se que ainda não haja consenso sobre o significado de accountability tanto na administração pública federal como na sua aplicação mais geral. Até o presente momento, a literatura, que busca uma interpretação conceitual mais 
consensual indica não ter chegado a um consenso (Pinho \& Sacramento, 2009; Medeiros, Crantschaninov \& Silva, 2013).

Por fim, percebe-se que vem ocorrendo no Brasil, há três décadas, um processo de significação do conceito accountability. Esse processo de associação entre significante e significado ocorre por meio de uma construção social difusa (Barthes \& Duisit, 1975), na qual há a criação de associações e abstrações que dotam de sentido os sinais da linguagem (Bakhtin, 1979). Com efeito, o presente estudo avança ao demonstrar a significação do conceito accountability na Administração Pública Federal. Vale destacar que a língua, em seu uso prático, é inseparável de seu conteúdo ideológico (Bakhtin, 1979), de modo que a crescente utilização do termo accountability nos atos da administração pública indica que o esse conceito vem sendo internalizado pelos atores sociais.

\section{FUNDAMENTAÇÃO TEÓRICA}

\section{O Conceito}

A democracia representativa é uma solução de governança para as ineficiências da democracia direta. O sistema democrático atual encontra-se a três passos de distância da democracia direta. O primeiro passo é a eleição de representantes do povo; o segundo ocorre quando os representantes eleitos delegam poderes a terceiros, nomeados e removidos por aqueles; um terceiro passo é tomado com a designação de uma pessoa que não é eleita nem nomeada politicamente, mas escolhida com base em critérios estabelecidos, como o concurso público, por exemplo. Como um serviço público assim constituído, distante da democracia direta, pode operar de forma compatível com a democracia? (Mosher, 1968)

A resposta para tal questionamento passa pelo conceito de responsabilidade, o qual possui duas conotações distintas, uma objetiva e outra subjetiva. A dimensão objetiva trata da responsabilidade de uma pessoa ou organização perante outra, por alguma atividade ou algum tipo de desempenho. Desse modo, se uma pessoa falhar em executar diretivas legítimas, será julgada responsável e estará sujeita a penalidades. Este significado é aparentado ao de accountability. Já no que se refere à dimensão subjetiva, o foco não está em quem ou pelo quê alguém é responsável, mas quem e pelo quê alguém se sente responsável e comportase de forma responsável. Esse significado está mais próximo de um sinônimo para identificação, lealdade e consciência, do que accountability ou answerability (Mosher, 1968).

Este conceito está diretamente relacionado ao de democracia. A tendência é a de que, quanto mais enraizados os valores democráticos na sociedade, maior a accountability. O contrário também é verdadeiro, ou seja, acountability é uma condição necessária para haver democracia, uma vez que a ausência de controle efetivo e responsabilização tenderiam a fragilizá-la (Campos, 1990). Ademais, em uma sociedade com accountability plena, espera-se que os gestores públicos prestem contas de suas ações, confiram publicidade a suas decisões e consultem a sociedade antes da tomada das decisões mais importantes (Akutsu \& Pinho, 2002). Vale destacar que a esfera púbica é construída por meio do diálogo (Cezar \& Barbosa, 2016), sem o qual não há participação social, o que enfraquece o aspecto democrático da accountability. 
Accountability refere-se à relação entre duas partes, em que a primeira delega responsabilidade para a segunda, que deverá exercer a gestão dos recursos, o que gera uma obrigação de prestação de contas da segunda parte perante a primeira (Akutsu \& Pinho, 2002; Pinho \& Sacramento, 2009; Tomio \& Filho, 2013). É possível perceber que a necessidade de accountability surge de uma relação semelhante à relação de agência, a qual envolve um contrato em que uma pessoa (principal) emprega outra (agente) para executar, em seu nome, um serviço que implique a delegação de algum poder de decisão do agente (Jensen \& Meckling, 2008).

Partindo-se dos pressupostos de que há racionalidade limitada e tendência ao oportunismo dos agentes (Williamson, 1996), a relação entre principal e agente incorre em custos de monitoramento voltados à limitação de atividades irregulares do agente. Tais mecanismos de monitoramento envolvem, mas não se limitam a: sistemas formais de controle, auditoria, restrições orçamentárias e sistemas de incentivo (Jensen \& Meckling, 2008), abarcando também mecanismos de estímulo à comunicação ativa de duas vias entre principal e agente (Lashgari, 2004), o que implicaria na redução da assimetria de informações entre essas partes.

Levando em conta essa preocupação constante com o controle do exercício do poder, a noção de accountability traz duas conotações básicas: answerability e enforcement. O primeiro se refere à obrigação dos agentes públicos de informar sobre seus atos, além de fornecer explicações aos interessados. Enforcement, por sua vez, representa a capacidade das agências de controle de impor sanções sobre os detentores de poder que violam seus deveres públicos (Schedler, 1999).

Answerability implica a obrigação de responder a dois tipos básicos de perguntas: informativas e explicativas. Envolve, portanto, o direito de receber informação e a obrigação correspondente de entregar todos os detalhes necessários, assim como o direito de receber uma explicação e a obrigação correspondente de justificar a conduta de alguém. Desse modo, a noção de accountability limita o detentor de poder não apenas por normas legais, mas também pela lógica da razão pública (Schedler, 1999).

Além de sua dimensão informacional e de seus aspectos explicativos, accountability contém elementos de enforcement, que está relacionado à premiação do bom e punição do mau comportamento ou desempenho. Isso implica a ideia de que os atores sujeitos a accountability não apenas tenham comportamentos postos em questão, mas também sejam responsabilizados pelos comportamentos impróprios (Schedler, 1999).

Por conseguinte, entende-se que o conceito de accountability, possui três dimensões características, relativas a informação, justificação e punição ou recompensa. Trata-se de variáveis contínuas que se mostram em diferentes graus, com diversas formas e ênfases (Schedler, 1999).

A dimensão informacional é bem relacionada ao conceito de transparência; pois, ao demandar informação, procura-se esclarecer os meandros da política. De fato, as instituições de accountability apenas sobrevivem na luz da esfera pública não resistindo às sombras da privacidade (Schedler, 1999), transparência exerce influência essencial sobre os stakeholders (Ribeiro, 2016). Vale destacar que há duas formas de transparência: ativa e passiva. A divulgação de informação de forma espontânea pelo Poder Público caracteriza a transparência ativa. Já a solicitação de acesso à informação pelos cidadãos aos órgãos governamentais caracteriza a transparência passiva (Cruz, Silva, \& Spinelli, 2016). Ao que parece, a dimensão informacional proposta por Schedler (1999) apenas abrangeria a transparência passiva, pois se 
refere ao ato de perguntar, de solicitar a informação. No entanto, neste estudo, entende-se que transparência ativa também é relevante para o processo de accountability, uma vez que busca a redução da assimetria de informações tão característica da relação entre Estado e sociedade.

A dimensão de justificação, por sua vez, refere-se à atividade de prestação de contas, uma vez que, ao demandar que o agente público justifique seus atos, objetiva-se entender os motivos que o levaram a decidir de determinada maneira. Com efeito, o significado de answerability ultrapassa o de transparência, uma vez que se expressa na obrigação dos agentes públicos prestarem contas sobre seus atos, além do dever de informar (Sacramento \& Pinho, 2016).

A própria análise das contas prestadas pode acarretar na responsabilização do agente público (Pinho \& Sacramento, 2009). Desse modo, os agentes públicos não apenas são passíveis de terem suas ações colocadas em questão, mas de suportar as consequências por seus atos (Schedler, 1999). Deste modo, a dimensão de punição ou recompensa está diretamente ligada à responsabilização objetiva do agente público por seus atos.

Accountability, portanto, pode ser entendida por meio desse conceito tridimensional que envolve transparência, prestação de contas e responsabilização em um processo contínuo, conforme representa a Figura 1. Cada uma de suas dimensões depende da realização da dimensão anterior, de modo que todas são necessárias para que haja accountability e nenhuma das dimensões é suficiente por si só. Em suma, accountability tem início necessariamente pela transparência pública, seja esta ativa e/ou passiva, e só se conclui após a responsabilização, na forma de recompensa ou de punição.

Figura 1 - Dimensões do conceito de Accountability

Transparência

Fonte: elaborada pelos autores.
Prestação de Contas

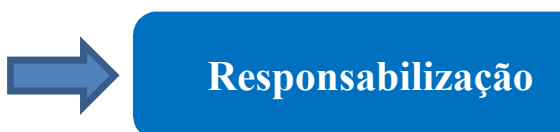

\section{Estudos Recentes}

Com o intuito de avaliar a adesão desse conceito ao que vem sendo tratado recentemente na literatura nacional, foi realizada uma busca por estudos em periódicos nacionais do estrato " $A$ " da classificação Qualis/CAPES para o campo Administração, Ciências Contábeis e Turismo, utilizando-se a palavra-chave "accountability" na indexação dos artigos. O período de tempo considerado para a coleta de artigos foi de janeiro de 2011 a abril de 2017, o que se deveu ao fato de Medeiros et al. (2013) terem realizado levantamento anterior incluindo apenas parcialmente o ano de 2011.

Um trabalho que merece destaque trata-se de uma meta-análise como objetivo de organizar as abordagens sobre accountability e situar este termo no debate acadêmico, promovendo um panorama de seu uso (Medeiros, Crantschaninov, \& Silva, 2013). Nesse trabalho, foi identificada uma confusão quanto ao uso do termo accountability, com diversas interpretações sobre seu significado, inclusive interpretações equivocadas ou incompletas. No entanto, concluiu que accountability está relacionada principalmente às ideias de responsabilidade e prestação de contas (Medeiros, Crantschaninov, \& Silva, 2013). É importante 
destacar que os resultados dessa pesquisa apresentam transparência como o terceiro elemento mais citado nas definições consideradas, após responsabilização e prestação de contas. Desta forma, verifica-se que as três dimensões de accountability estão presentes na literatura, em maior ou menor grau.

Estudos recentes sobre o tema têm focado em pelo menos uma dessas dimensões de accountability. Alguns buscam relacionar transparência e/ou prestação de contas com responsabilização, de modo que esta dimensão é tida como um efeito das demais, corroborando o entendimento da accountability como um processo.

Estudos que possuem maior enfoque na dimensão de transparência buscam majoritariamente avaliar os instrumentos que permitem a realização desta dimensão em órgãos ou políticas públicas (Raupp \& Pinho, 2013; 2016; Cruz, Silva, \& Spinelli, 2016; Faria \& Streit, 2016). A transparência é vista como capaz de contribuir para a redução da corrupção no espaço público ao mesmo tempo em que estabelece relações entre o Estado e a sociedade civil mais democrática (Raupp \& Pinho, 2013).

Os artigos com maior enfoque na dimensão prestação de contas, por sua vez, têm majoritariamente como objeto de pesquisa agências de controle da administração pública. Tais trabalhos abordam o aspecto horizontal de accountability, ou seja, tratam do controle exercido pelos órgãos públicos, ignorando o controle social sobre a administração pública, e colocam a tomada de contas como dimensão central no processo (Rocha, 2013; Quintão \& Carneiro, 2015; Reis, Dacorso, \& Tenório, 2015).

Com enfoque não apenas em prestação de contas, mas em ambos os aspectos, informacional e de justificação, que envolvem o conceito de answerability, merece destaque também o trabalho de Sacramento e Pinho (2016), que realiza a identificação e análise de mudanças institucionais formais, ocorridas em nível federal no Brasil, que favoreçam os requisitos típicos de answerability. Os autores inferem que answerability, não obstante constitua um passo necessário para o início do processo de accountability, encontra obstáculos para se consolidar em sistemas que possuam uma cultura política fortemente marcada pelo patrimonialismo e práticas autoritárias, embora sejam democráticos. Após análise de institutos legais e constitucionais, conclui-se que a construção da trajetória de answerability no Brasil contemporâneo é contínua, ainda que revele certas dificuldades em sua consolidação. Salienta-se que uma série de medidas institucionais sobre o tema foram introduzidas no contexto nacional, de modo que atualmente não se trata apenas questões de natureza orçamentária e financeira, como originalmente se tratava, como também assuntos profundamente democráticos (Sacramento \& Pinho, 2016).

Já as pesquisas com maior atenção à dimensão de responsabilização apenas tangenciam o tema accountability em suas análises e discussões. No entanto, tais estudos destacam a face punitiva do processo tanto ao ressaltar sua importância (Silva, 2012; Inamine, Erdmann, \& Marchi, 2012; Gomes, 2015), quanto ao defender a necessidade de seu abrandamento em alguns casos, sem que isso deixe de inibir a ação auto interessada dos agentes públicos (Oliveira, 2012). Alguns desses estudos privilegiam o aspecto vertical da accountability ao destacar a necessidade da participação social para a responsabilização de agentes públicos. Busca-se, assim, a inserção de grupos sociais ao longo do ciclo de políticas públicas (Silva, 2012; Ceneviva \& Farah, 2012; Gomes, 2015; Schommer, Rocha, Spaniol, Dahmer, \& Sousa, 2015; Braga \& Gomes, 2016; Pinheiro, 2016). 
Em suma, observa-se que a maior parte dos estudos recentes sobre accountability enfoca uma das dimensões desse conceito. Tais estudos não apresentam uma visão holística do processo de accountability. A adoção dessa perspectiva fragmentada para tratar o tema negligencia o fato de que todas as dimensões do processo são necessárias para que haja de fato controle sobre a administração pública.

\section{Tipos Ideais}

Accountability tem sido frequentemente estudada por meio de um arquétipo que abrange duas dimensões didáticas, vertical e horizontal. A dimensão vertical aborda o controle dos gestores públicos pelos eleitores. Já na dimensão horizontal, accountability está relacionada a uma rede de instituições capazes de questionar e punir os agentes públicos pelo cumprimento impróprio de suas responsabilidades. Em democracias representativas consolidadas, accountablity opera em sentido vertical, em relação àqueles que elegeram o representante, bem como em sentido horizontal, no que se refere a uma rede institucional relativamente autônoma capaz de questionar e punir comportamentos impróprios (O'Donnell, 1991).

Outras formas de classificação de accountability também são vistas na literatura, mas com menor frequência. Schedler (1999) sugere as seguintes variedades: política, relativa à retidão das políticas e ao processo de formulação de políticas públicas; administrativa, que revisa a correição dos atos burocráticos; profissional, relacionada aos padrões éticos das classes profissionais; financeira, a qual sujeita o uso de dinheiros públicos às normas de austeridade, eficiência e propriedade; moral, que avalia os atos públicos com base nos padrões normativos; legal, que monitora a observância das leis; e constitucional, que avalia se os atos legislativos estão de acordo com as regras constitucionais (Schedler, 1999).

Abrucio e Loureiro (2004), por sua vez, elencam três formas de accountability em uma visão complementar à de O'Donnell: processo eleitoral, controle institucional durante os mandatos e regras estatais intertemporais. Accountability durante o processo eleitoral é exercida por meio do sistema partidário, de debates e demais formas de disseminação da informação e da definição clara de regras de financiamento de campanhas. No que tange ao controle durante os mandatos, vale ressaltar os controles parlamentar e judicial, bem como controles administrativos procedimentais, como o exercido pelos Tribunais de Contas, o controle do desempenho da ação governamental e o controle social. A terceira forma se dá por meio de regras atemporais que limitam o poder governamental em prol dos direitos individuais e coletivos da sociedade (Abrucio \& Loureiro, 2004).

Recentemente, foi proposto um modelo que facilita o entendimento do complexo quadro em que o construto accountability está inserido, o qual abrange quatro estágios de interação entre Estado e sociedade para a coprodução de controle e informação: clássico, transversal, sistêmico e difuso. O estágio de accountability clássica seria aquele em que não há coprodução de controle e informação entre Estado e sociedade. Nesse estágio, accountability vertical apresenta-se dissociada da horizontal. Em seguida, o estágio transversal envolve alguma interação entre os mecanismos horizontais e verticais de accountability para produção, disseminação e uso da informação. O estágio sistêmico, por sua vez, abrange o trabalho conjunto e com regras complementares e interconectadas entre cidadãos e Estado para a produção de informação e controle. Finalmente, no estágio de accountability difusa, informação e controle são igualmente produzidas por Estado e sociedade, sem que haja uma estrutura central, mas uma rede capaz de envolver 
grande variedade de mecanismos políticos e institucionais (Schommer, Rocha, Spaniol, Dahmer, \& Sousa, 2015).

Observa-se, portanto, a evolução das formas como se exerce e como se percebe a accountabilty. À medida que o termo se carrega de sentido na linguagem, conceito é internalizado na cultura, e a tendência é a de que haja uma maior quantidade de mecanismos de accountability, bem como maior participação social no controle da administração pública. Essa evolução pode ser observada na utilização crescente do termo accountability nos atos da Administração Pública Federal, conforme relatado nos resultados deste artigo.

\section{METODOLOGIA}

Este estudo possui caráter descritivo, uma vez que identifica a utilização do termo accountability e seus significados nos atos da Administração Pública Federal. Quanto à natureza, o estudo pode ser considerado misto, uma vez que a análise dos dados abrangeu técnicas quantitativas, de contagem das observações, e qualitativas, mediante as quais se buscou entender os significados atribuídos ao termo accountability.

A coleta de dados ocorreu mediante uma busca por atos da administração pública federal no portal da Imprensa Nacional (http://portal.imprensanacional.gov.br), em junho de 2017, utilizando-se o termo "accountability" como palavra chave. A busca abrangeu todas as seções do Diário Oficial da União - DOU -, estendendo-se desde janeiro de 1990 (ano mais anterior em que a ferramenta permite busca) até dezembro de 2017. Tal busca retornou 211 atos, todos infralegais, entre portarias, despachos, editais, resoluções, acórdãos, etc. Destaca-se que não houve retorno para o período de 1990 a 1993, de modo que o termo accountability foi expresso em um ato do Governo Federal pela primeira vez em 1994. Vale ressaltar também que o escopo deste estudo se restringe aos atos administrativos, não abarcando os jurisdicionais ou legislativos.

Os atos dos diversos órgãos da administração pública federal foram analisados por meio de uma abordagem diretiva de análise de conteúdo. Esta abordagem possui uma aplicação dedutiva, em que se buscam questões alvo sobre categorias predeterminadas (Hsieh \& Shannon, 2005). Para tanto, os atos foram ordenados em uma planilha de análise, mediante a qual se avaliaram suas datas de publicação, o tipo de ato, o órgão responsável pela publicação e Poder da República a que está vinculado, o objeto de cada ato, a definição de accountability adotada e o contexto em que o termo foi utilizado. Tais informações foram sintetizadas e agrupadas no decorrer da análise. Destaca-se também que as categorias de análise foram predeterminadas pelos autores sem que houvesse a validação por pares.

Vale destacar que três documentos encontrados não são de órgãos ou entidades vinculados ao setor público. Tratam-se de avisos de alteração de grade curricular, os quais incluem disciplinas com o termo accountability em seu título em cursos de Ciências Contábeis de instituições de ensino superior particulares. Por não serem atos de órgãos ou entidades do setor público, tais documentos foram descartados. Foi descartado também uma decisão do Tribunal Regional Federal da $1^{\text {a }}$ Região, por se tratar de ato jurisdicional, não administrativo. 


\section{ANÁLISE DOS RESULTADOS}

O termo accountability foi primeiro citado em um ato da administração pública federal em 1994, em um comunicado do Ministério de Ciência e Tecnologia. Tratava-se da renovação do cadastro de um programa de computador denominado "Infoguard Accountability Facility", o qual permitia que o administrador de segurança do sistema definisse e implementasse critérios de auditoria. Comunicado semelhante foi publicado em 1995 e 1996.

Em 1995, foi publicada uma ata do TCU na qual se relata a participação de um ministro daquele Tribunal em um seminário internacional de controle externo, ocasião em que houve uma palestra sobre "Accountability no Setor Público e os Desafios da Auditoria Integrada Governamental". Já em 1996, o então Presidente da República participou de uma solenidade no TCU, na qual citou, em seu discurso, o termo accountability, relacionando-o com a necessidade da Administração Pública de transparência, prestação de contas e responsabilidade perante a sociedade pelo que se faz.

Verifica-se que o surgimento do termo accountability em atos da administração pública federal se deu de forma tímida, em atos e momentos esparsos. De 1994 a 1996, o termo foi citado em apenas cinco documentos, sendo que três deles referiam-se ao mesmo objeto, contratação de um programa de computador cujo nome contém a palavra accountability.

Conforme se observa na Figura 2, o termo passou a ser citado com maior frequência nos atos da administração pública federal a partir do ano de 2008, com uma tendência de crescimento desde então. É possível afirmar, portanto, que este conceito tornou-se mais relevante no âmbito da União na última década, acompanhando o aumento de sua importância no contexto acadêmico nacional, que se deu após 2006 (Medeiros, Crantschaninov, \& Silva, 2013).

Figura 2 - Frequência absoluta dos atos publicados pela Administração Pública Federal de 1994 a 2017.

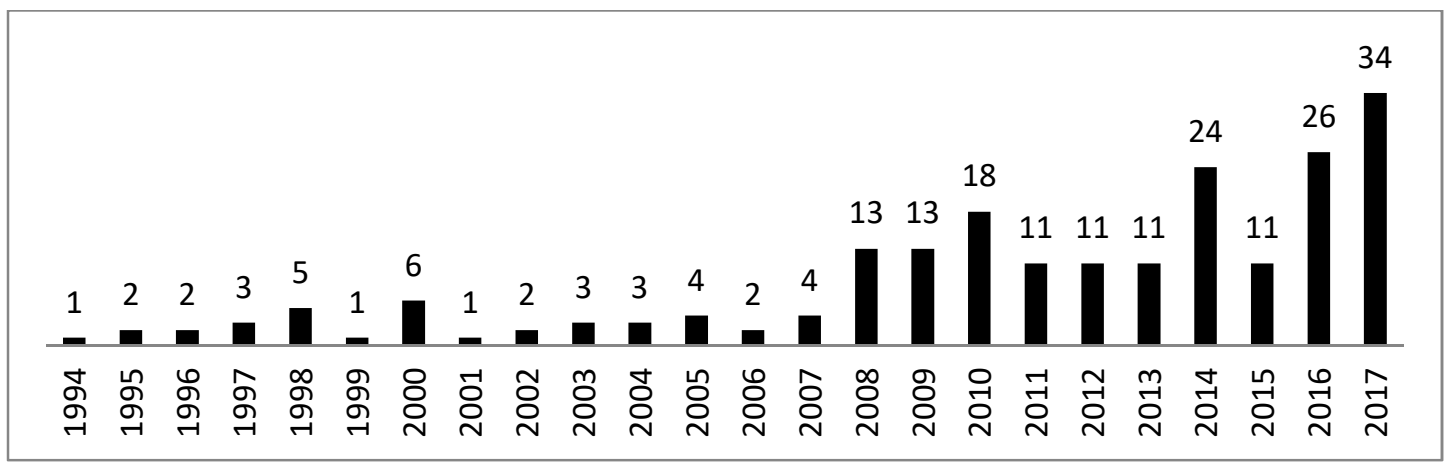

Fonte: elaborada pelos autores.

No que se refere aos tipos de atos em que o termo accountability foi citado, os editais foram os mais utilizados, conforme Figura 3. Tais instrumentos contêm majoritariamente regras e critérios de concursos para provimento de cargos e empregos públicos. Nesses casos, o termo accountability constava como tema contido no conteúdo programático do concurso. Vale ressaltar que accountability surge como tópico a ser cobrado em concurso público em 2000, quando compôs o conteúdo programático de provas para as carreiras da Secretaria do Tesouro Nacional, Secretaria Federal de Controle Interno do Ministério da Fazenda (atual 
Ministério da Transparência e Controladoria-Geral da União - CGU) e do Ministério do Planejamento, Orçamento e Gestão (atual Ministério do Planejamento, Desenvolvimento e Gestão - MPDG).

Figura 3 - Frequência dos tipos de atos em que o termo accountability foi citado

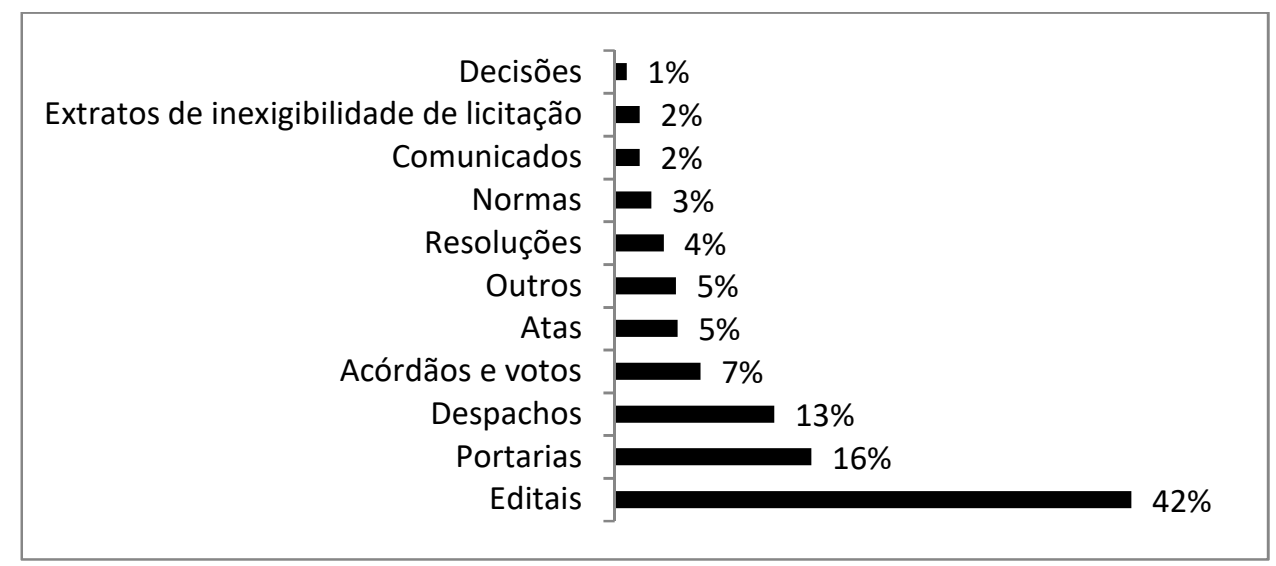

Fonte: elaborada pelos autores.

Destaca-se que, em 2008, ano que marca uma elevação abrupta no número de citações do termo accountability no DOU, $45 \%$ dos atos publicados foram editais. Em resumo, foram sete editais de concursos para provimento de cargos e empregos públicos e um edital de resultado do concurso de monografias da CGU, no qual a monografia vencedora no tema Combate à Corrupção era intitulada "Internet e Accountability: um estudo sobre a acessibilidade às informações orçamentárias através do site Contas Abertas". A grande ocorrência do tema em conteúdo programático de concursos públicos indica uma preocupação com que noções de accountability estejam presentes nos conhecimentos e habilidades dos futuros servidores.

Após os editais, são frequentes também os despachos e as portarias, com $13 \%$ e $16 \%$ respectivamente. Os despachos, assim como parte das portarias, foram utilizados para autorizar o afastamento de agentes públicos do país para participação em eventos internacionais que tratavam do tema accountability. Ressalta-se que tais afastamentos se iniciaram em 1998, tendo uma dispersão homogênea por todo o período avaliado.

As portarias que não se referem aos afastamentos de agentes públicos do país são mais recentes e tratam de assuntos diversos. Exemplos desses assuntos são: programa de curso de aperfeiçoamento de servidores, sendo accountability tema de palestra do programa; fixação de metas de desempenho de órgãos públicos, o desenvolvimento de accountability seria uma meta definida; concurso de boas práticas, sendo accountability um objetivo a ser alcançado com o concurso; instituição planejamento estratégico, de modo que accountability é elencado como princípio norteador do sistema instituído; definição de política de gestão de riscos, governança e controles internos, entre outros.

Onze portarias ou resoluções publicadas em 2017 tratam do estabelecimento de política de gestão de riscos, governança e controles internos de órgãos públicos. Tais instrumentos foram provocados por uma Instrução Normativa Conjunta do MPDG e CGU, que estabelece a obrigatoriedade de os órgãos do Poder Executivo federal adotarem medidas para sistematizar práticas de gestão de riscos, governança e controles internos. Esses atos trazem definições de accountability bastante similares, baseadas principalmente no 
conceito de responsabilidade objetiva. Contudo, um padrão que se repete nesses documentos é que, apesar de haver uma definição para accountability, o termo apenas é citado uma vez. Ou seja, não se apresenta accountability como um objetivo ou um princípio da política de gestão de riscos.

Em seguida, acórdãos e votos de Ministros do TCU aparecem em sete por cento dos registros. Estes instrumentos tratam de apreciação de contas e auditorias operacionais em órgãos e entidades públicas. Accountability é frequentemente citada nesses documentos como um princípio constitucional relacionado à prestação de contas daqueles que administram bens ou recursos públicos.

Nesse contexto, accountability tem sido encarado como um conceito mais estreito do que o tratado na literatura, abrangendo em maior extensão a dimensão horizontal (O'Donnell, 1991), na prestação de contas às agencias de controle. O que permitiria descrever o estágio de accountability, na tipologia de Schommer et al. ( 2015), como clássica, uma vez que não se percebe interação entre os mecanismos horizontais e verticais de accountability para produção, disseminação e uso da informação. Acerca do Poder da República em que o órgão responsável pelo ato está vinculado, observa-se que os atos do Executivo representam cerca de $76 \%$ do total, os do Poder Legislativo, $21 \%$, os do Poder Judiciário e os dos órgãos autônomos do Sistema de Justiça representam juntos cerca de $3 \%$, conforme a Tabela 1.

Tabela 1 - Frequências de observações em relação aos Poderes da República e órgãos a estes vinculados

\begin{tabular}{|c|c|c|}
\hline Poderes/Órgãos & $\begin{array}{c}\text { Frequência } \\
\text { Absoluta }\end{array}$ & $\begin{array}{c}\text { Frequência } \\
\text { Relativa }\end{array}$ \\
\hline \multicolumn{3}{|l|}{ Executivo } \\
\hline Ministério da Educação & 44 & \multirow{21}{*}{$75,8 \%$} \\
\hline Ministério da Fazenda & 26 & \\
\hline Ministério da Transparência e Controladoria-Geral da União & 16 & \\
\hline Ministério da Justiça e Segurança Pública & 11 & \\
\hline Presidência da República & 9 & \\
\hline Ministério do Planejamento, Desenvolvimento e Gestão. & 8 & \\
\hline Ministério da Ciência, Tecnologia, Inovação e Comunicações & 7 & \\
\hline Ministério do Meio Ambiente & 6 & \\
\hline Ministério de Minas e Energia & 5 & \\
\hline Ministério dos Transportes, Portos e Aviação Civil & 4 & \\
\hline Ministério da Integração Nacional & 4 & \\
\hline Ministério da Defesa & 3 & \\
\hline Ministério da Indústria, Comércio Exterior e Serviços & 3 & \\
\hline Ministério da Cultura & 2 & \\
\hline Ministério da Saúde & 2 & \\
\hline Ministério das Cidades & 2 & \\
\hline Ministério do Esporte & 2 & \\
\hline Advocacia-Geral da União & 1 & \\
\hline Ministério do Trabalho e Emprego & 1 & \\
\hline Ministério da Agricultura, Pecuária e Abastecimento & 1 & \\
\hline Conselho Federal de Contabilidade & 3 & \\
\hline \multicolumn{3}{|l|}{$\begin{array}{ll}\text { Legislativo } \\
\end{array}$} \\
\hline Tribunal de Contas da União & 38 & \\
\hline Câmara dos Deputados & 6 & $21,3 \%$ \\
\hline Senado Federal & 1 & \\
\hline \multicolumn{3}{|c|}{ Judiciário e Órgãos Autônomos do Sistema de Justiça } \\
\hline Ministério Público da União & 4 & \\
\hline Justiça Eleitoral & 1 & $2,8 \%$ \\
\hline Defensoria Pública da União & 1 & \\
\hline
\end{tabular}

Fonte: elaborada pelos autores. 
No que se refere ao Poder Executivo, merece destaque o Ministério da Educação, cujos concursos públicos para provimento de cargos em instituições públicas de ensino superior comumente contêm o tema accountability em seus conteúdos programáticos. Além disso, os professores de magistério superior estão entre os servidores públicos que mais viajam para eventos internacionais sobre o assunto. Cumpre destacar também o Ministério da Fazenda e a CGU, que igualmente costumam cobrar os conhecimentos relacionados a accountability nas provas de concurso para suas principais carreiras e liberar servidores para eventos internacionais. Ressalta-se que a CGU é signatária de documentos que induzem a observância da accountability na administração pública federal, como a Instrução Normativa Conjunta com o MPDG, supracitada, além de promover estudos sobre o tema mediante a instituição de grupos de trabalho ou concursos de monografias e de boas práticas de gestão.

Os atos de órgãos que compõem o Poder Legislativo representam cerca de $21 \%$ das observações. A maior parte desses atos é do TCU, cujos membros citam accountability como um princípio constitucional em suas decisões. Essa Corte de Contas procura difundir o conceito mediante recomendações de sua observância pelos órgãos auditados, além da capacitação de pessoal no assunto. Vale destacar também que a Câmara dos Deputados oferece um curso de Mestrado Profissional em Poder Legislativo no qual accountability é tema de uma de suas linhas de pesquisa.

É notável a baixa quantidade de atos que citam o termo accountability no Senado Federal. O Legislativo é o Poder que está mais próximo da democracia direta, a apenas um passo de distância, conforme classificação de Mosher (1968). Em tese, os órgãos do Poder Legislativo deveriam ser os maiores facilitadores da participação e controle social das políticas públicas. Vale salientar que diversos estudos destacam a importância da participação social para a ocorrência de accountability (Ceneviva \& Farah, 2012; Schommer, Rocha, Spaniol, Dahmer, \& Sousa, 2015; Pinheiro, 2016; Braga \& Gomes, 2016).

O Poder Judiciário, por sua vez, pouco cita o termo accountability em seus atos administrativos. Foi observado apenas um ato em que o termo ocorreu. Em 2009, o termo accountability foi listado como tema a ser cobrado no concurso público para provimento de cargos do Tribunal Regional Eleitoral do Ceará. No que tange aos órgãos autônomos integrantes do Sistema de Justiça, o Ministério Público da União - MPU - foi signatário de quatro atos registrados e a Defensoria Pública da União - DPU -, de um. Merece destaque, portaria do MPU que estabelece orientações para prestação de contas do exercício de 2016, na qual a necessidade de accountability é listada como relevante. Já no caso da DPU, accountability foi tema constante do conteúdo programático de concurso público para seus quadros administrativos.

Além de ter tido pouca referência nos atos publicados pelas organizações do Sistema de Justiça como um todo, accountability também é pouco estudada nesse contexto. Os resultados apresentados por Medeiros et al. (2013) indicam uma escassez de pesquisas sobre accountability em organizações do Sistema de Justiça. Dentre os 53 artigos encontrados naquele trabalho, apenas dois tratavam desse locus, sendo que ambos não se referem ao Poder Judiciário propriamente dito, mas ao Ministério Público (Medeiros, Crantschaninov, \& Silva, 2013). A atualização conduzida no presente estudo também não retornou produção acadêmica sobre accountability nessas organizações.

Os controles parlamentar e judicial são formas relevantes de controle institucional no decorrer dos mandatos (Abrucio \& Loureiro, 2004). Nesse sentido, a baixa participação dos órgãos do Poder Judiciário e do Congresso Nacional, em especial o Senado Federal, nas observações é uma questão sintomática, pois se 
verifica o enfrentamento de um problema de accountability de segunda ordem (Schedler, 1999) e o descolamento desses entes em relação aos demais em uma questão intrinsicamente ligada à democracia.

Dando sequência, 40 registros analisados traziam direta ou indiretamente uma definição para o termo accountability. Com base nos elementos considerados nos conceitos mais comumente utilizados pela literatura sobre o tema (Medeiros, Crantschaninov, \& Silva, 2013), bem como nos termos utilizados nas definições ora analisadas, foram definidos marcadores e feita sua contagem nas definições do termo accountability adotadas nos atos da administração pública federal, cujos resultados seguem apresentados na Tabela 2.

Tabela 2 - Marcadores considerados nos conceitos de accountability adotados pela administração pública federal

Categorias

Prestação de Contas

Prestação de contas; prestar contas; prestação sistemática de contas.
Marcadores

Contagem
Responsabilidade

Responsabilização

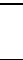


obrigação de accountability atores que não utilizam, arrecadam ou gerenciem dinheiros, bens ou valores públicos, mas são responsáveis por decisões com grande impacto social, especialmente os legisladores e juízes. Nota-se que essa forma de limitação do conceito de accountability vai ao encontro da abordagem de trabalhos acadêmicos que possuem Tribunais de Contas como objeto de estudo (Rocha, 2013; Quintão \& Carneiro, 2015; Reis, Dacorso, \& Tenório, 2015). Nesse caso, o foco está nos aspectos horizontal (O'Donnell, 1991) e financeiro (Schedler, 1999) de accountability, não se explorando a possibilidade de coprodução de informação e controle com a sociedade, que envolve alguma forma de interação entre os mecanismos horizontais e verticais de accountability (Schommer, Rocha, Spaniol, Dahmer, \& Sousa, 2015).

Em segundo lugar, surgem os termos "responsabilidade" e "responsabilização", bem como "responsabilizar-se" e "responsáveis". Embora essas palavras possuam o mesmo radical, seus significados são distintos. Responsabilidade pode ser entendida em sentido objetivo ou subjetivo. Responsabilidade objetiva refere-se ao dever de uma pessoa ou organização responder perante outra. Trata-se, portanto de uma obrigação exigida de fora para dentro. Responsabilidade subjetiva, por sua vez tem o foco em para quem ou para quê uma pessoa sente-se e comporta-se de forma responsável. Portanto, o conceito de responsabilidade objetiva está mais relacionado ao de accountability. Já o de responsabilidade subjetiva seria sinônimo de lealdade ou identificação (Mosher, 1968).

Responsabilização, por sua vez, refere-se ao ato ou efeito de imputar responsabilidade a alguém. Em resumo, accountability surge do ato de uma pessoa assumir o poder delegado por outro, do qual se exige prestação de contas, de modo que a avaliação das contas prestadas pode acarretar em responsabilização (Pinho \& Sacramento, 2009). Nesse sentido, responsabilização seria sinônimo de enforcement, ou seja, sujeição a prêmio ou punição pelo comportamento ou desempenho (Schedler, 1999; Sacramento \& Pinho, 2016).

Nesse sentido, foram definidas duas categorias distintas, Responsabilização, composta por observações relacionadas aos termos "responsabilização", "responsabilizar-se", "consequência de seus atos e omissões" e "sanção"; e Responsabilidade, que engloba as observações que contenham os termos "responsabilidade" e "responsáveis". Algumas observações relacionadas à categoria Responsabilidade destacam-se por envolverem o aspecto vertical de accountability, destacado por O'Donnell (1991). Ou seja, colocam a sociedade como foco da accountability.

Em seguida, o termo "transparência" foi citado em seis ocasiões e "transparente" em uma. Há também referência ao "direito de a sociedade ser devidamente esclarecida" a respeito de determinados assuntos, bem como "comunicação", que também poderia ser considerado um conceito análogo. Ressalta-se que, assim como observado por Medeiros et al. (2013) ao analisar a literatura acadêmica sobre accountability, transparência possui uma menor importância em relação às demais dimensões também para os agentes públicos.

Vale destacar que transparência é basilar para haver accountability, pois implica a redução da assimetria de informações entre Estado e a sociedade. Conforme colocado por Schedler (1999), não há que se falar em accountability fora da luz da esfera pública. Ressalta-se também que a transparência ativa, relacionada a divulgação espontânea de informações pelo Poder Público (Cruz, Silva, \& Spinelli, 2016), não foi explicitamente citada em nenhum dos documentos encontrados. Desse modo, percebe-se que o conceito 
de transparência ainda não está intimamente associado a accountability na administração pública federal brasileira.

Verifica-se, portanto, que a administração pública federal confere maior relevância à dimensão "prestação de contas" em detrimento das demais dimensões de accountability. Contudo, as dimensões "transparência" e "responsabilização" também são citadas nas tentativas de definição e accountability nos atos da União.

Considerando o que era esperado inicialmente, o termo accountability de fato vem sendo cada vez mais utilizado nos atos da administração pública federal. Isso indica um processo de construção social em torno da significação do termo. Ou seja, o conceito vem sendo internalizado pelos atores sociais. Contudo, a internalização ainda não abrange por completo questões relacionadas a transparência ou participação social. No que se refere aos órgãos públicos signatários dos atos observados neste estudo, os órgãos de controle, como o TCU e a CGU, de fato, tiveram posição de destaque. Entretanto, não se esperava que fossem observados tantos atos citando accountability nos ministérios da Educação e da Fazenda, o que surpreende positivamente. Finalmente, verificou-se que, conforme o colocado por Pinho e Sacramento (2009) e Medeiros et al. (2013), ainda não há consenso acerca do significado de accountability, uma vez que não se percebe uma posição majoritária em torno de uma definição.

\section{CONCLUSÃO}

O objetivo deste trabalho foi o de identificar a utilização do termo accountability na administração pública federal brasileira ao longo do tempo. Para tanto, realizou-se um levantamento e análise dos atos publicados pela administração pública federal no DOU, mediante a ferramenta de busca disponível no portal da Imprensa Nacional. Após a exclusão de três registros, foram analisados 211 atos publicados no período de 1994 a 2017, como uma concentração e tendência de crescimento a partir do ano de 2008.

A análise se deu à luz da literatura sobre accountability. Os resultados permitem concluir que há um emprego crescente do termo nos atos da administração pública federal, indicando uma construção social de significado em torno do termo accountability. No entanto, a maior parte das definições adotadas nos atos observados tende a restringir o conceito apenas à dimensão prestação de contas, em especial aquelas encontradas nos acórdãos publicados pelo TCU, demonstrando um estágio inicial acerca da adoção do conceito na administração pública federal.

Vale destacar também que ainda não há uma posição majoritária sobre o conceito accountability. A maior parte dos termos utilizados para a definição de accountability abrangem prestação de contas, responsabilização e transparência. Contudo, são poucas as definições que colocam transparência, prestação de contas e responsabilização conjuntamente. Ademais, transparência foi a dimensão menos observada, indicando que esse conceito ainda não está intimamente associado a accountability na administração pública federal.

Os resultados indicam também um descompasso entre os Três Poderes da República na adoção desse termo. O Poder Executivo concentra a maior quantidade de atos, com destaque para os Ministérios da Educação, Fazenda e CGU. No Legislativo, o TCU é o responsável pela maior parte dos atos. A Câmara dos Deputados e principalmente o Senado pouco utilizam o termo em suas publicações. No caso do Judiciário, é 
notável a escassez de atos contendo o termo accountability. Esses dados devem ser observados com cautela, pois é possível que haja atos relacionados a accountability, mas que não citem o termo em inglês. Desse modo, não é possível afirmar que haja deficiência dos órgãos componentes do Poder Judiciário nesse tema.

O objetivo deste estudo não abrangeu a identificação de aspectos culturais acerca do construto accountability, mas restringiu-se à identificação da utilização do termo e seus significados. Para identificar os aspectos culturais, seria interessante a realização de pesquisa que verificasse os possíveis usos em português de termos que remetam a accountability. Talvez, as futuras buscas possam incluir a aparição simultânea dos termos "transparência", "prestação de contas" e "responsabilização", que definem accountability na língua portuguesa, ou até mesmo de termos ou expressões relacionados tais como identificados nesta pesquisa: consequência de seus atos e omissões; sanção; responsabilidade; comunicação, compromisso, etc.

O escopo deste estudo não alcança atos publicados em boletins de circulação interna. No entanto, considera-se que os atos de maior relevância foram todos considerados, pois estes devem sempre ser publicados no DOU. É possível também que, no decorrer do processo de elaboração dos documentos a serem publicados, o termo accountability tenha sido suprimido na tentativa de se evitar a utilização de estrangeirismo. Nesses casos, torna-se impossível a identificação dos significados adotados para o conceito de accountability. Por fim, as categorias de análise foram construídas pelos autores sem a validação por pares, o que aumentaria a confiabilidade da análise.

\section{REFERÊNCIAS}

Abrucio, F. L., \& Loureiro, M. R. (2004). Finanças Públicas, Democracia e Accountability. In: C. Biderman, \& P. Arvate, Economia do Setor Público no Brasil (pp. 75-102). Rio de Janeiro: Elsevier.

Akutsu, L., \& Pinho, J. G. (2002). Sociedade da informação, accountability e democracia delegativa: investigação em portais de governo no Brasil. Revista de Administração Pública, 36(5), 723-45.

Bakhtin, M. (1979). Marxismo e Filosofia da Linguagem. São Paulo: Hucitec.

Barthes, R., \& Duisit, L. (1975). An Introduction to the Structural Analysis of Narrative. New Literary History, 6(2), $237-272$.

Braga, L. V., \& Gomes, R. C. (2016). Participação Eletrônica e suas Relações com Governo Eletrônico, Efetividade Governamental e Accountability. Organizações \& Sociedade, 23(78), 487-506.

BRASIL. (1988). Constituição da República Federativa do Brasil. Brasília.

BRASIL. Presidência da República. (2002). Manual de redação da Presidência da República. Brasília: Presidência da República.

Campos, A. M. (1990). Accountability: quando poderemos traduzi-la para o português? Revista de Administração Pública, $24(2), 30-50$

Ceneviva, R., \& Farah, M. F. (2012). Avaliação, informação e responsabilização no setor público. Revista de Administração Pública, 46(4), 993-1016.

Cezar, L. C., \& Barbosa, T. R. C. (2016). Por uma Esfera Pública Efetivamente Publicizada: reflexões sobre a participação de gestores municipais na Política Nacional de Resíduos Sólidos. Pretexto, 17(1), 82-98.

Cruz, M. M., Silva, T. B., \& Spinelli, M. (2016). O papel das controladorias locais no cumprimento da Lei de Acesso à Informação pelos municípios brasileiros. Cadernos EBAPE.BR, 14(3), 721-743.

Faria, F. d., \& Streit, R. E. (2016). Governança em bancos centrais: um estudo comparativo das práticas de governança dos bancos centrais do Brasil, Canadá e Inglaterra. Revista de Administração Pública, 50(5), 765-794.

Gomes, E. G. (2015). Conselhos gestores de políticas públicas: aspectos teóricos sobre o potencial de controle social democrático e eficiente. Cadernos EBAPE.BR, 13(4), 894-909.

Hsieh, H.-F., \& Shannon, S. E. (2005). Three Approaches to Qualitative Content Analysis. Qualitative Health Research, 15(9), 1277-1288. 
Inamine, R., Erdmann, R. H., \& Marchi, J. J. (2012). Análise do sistema eletrônico de compras do governo federal brasileiro sob a perspectiva da criação de valor público. Revista de Administração - RAUSP, 47(1), 124-139.

Jensen, M. C., \& Meckling, W. H. (2008). Teoria da Firma: Comportamento dos Administradores, Custos de Agência e Estrutura de Propriedade. Revista de Administração de Empresas, 87-125.

Lashgari, M. (2004). Corporate Governance: theory and practice. The Journal of American Academy of Business, 46-51.

Medeiros, A. K., Crantschaninov, T. I., \& Silva, F. C. (2013). Estudos sobre Accountability no Brasil: meta-análise de periódicos brasileiros das áreas de administração, administração pública, ciência política e ciências sociais. Revista de Administração Pública, 47(3), 745-775.

Mosher, F. C. (1968). Democracy and the Public Service. New York: Oxford University Press.

O'Donnell, G. (1991). Democracia Delegativa? Novos Estudos(31), 25-40.

Oliveira, A. (2012). Burocratas da linha de frente: executores e fazedores das políticas públicas. Revista de Administração Pública, 46(6), 1551-73.

Pinheiro, D. R. (2016). A legitimidade do controle social da gestão pública: uma resposta a Herbert Wechsler. Revista de Administração Pública, 50(5), 867-883.

Pinho, J. G., \& Sacramento, A. S. (2009). Accountability: já podemos traduzi-la para o português? Revista de Administração Púbica, 1343-1368.

Quintão, C. M., \& Carneiro, R. (2015). A tomada de contas especial como instrumento de controle e responsabilização. Revista de Administração Pública, 49(2), 473-491.

Raupp, F. M., \& Pinho, J. G. (2013). Accountability em câmaras municipais: uma investigação em portais eletrônicos. Revista de Administração - RAUSP, 48(4), 770-782.

Raupp, F. M., \& Pinho, J. G. (2016). Review of passive transparency in Brasilian city councils. Revista de Administração RAUSP, 51, 288-298.

Reis, A. F., Dacorso, A. R., \& Tenório, F. G. (2015). Influência do uso de tecnologias de informação e comunicação na prestação de contas públicas municipais: um estudo de caso no Tribunal de Contas dos Municípios do Estado da Bahia. Revista de Administração Pública, 49(1), 231-251.

Ribeiro, H. C. M. (2016) Influência da Governança Corporativa nos Stakeholders das Entidades Esportivas. Pretexto, 17(3), 40-56.

Rocha, A. C. (2013). A realização da accountability em pareceres prévios do Tribunal de Contas de Santa Catarina. Revista de Administração Pública, 47(4), 901-25.

Sacramento, A. S., \& Pinho, J. G. (2016). The process of implementing answerability in contemporary Brazil. Revista de Administração Pública, 50(2), 193-213.

Schedler, A. (1999). Conceptualizing Accountability. In: A. Schedler, L. Diamond, \& M. F. Plattner, The Self-Restraining State: Power and Accountability in New Democracies (pp. 13-28). Boulder, Colorado : Lynne Rienner Publishers.

Schommer, P. C., Rocha, A. C., Spaniol, E. L., Dahmer, J., \& Sousa, A. D. (nov-dez de 2015). Accountability and coproduction of information and control: social observatories and their relationship with government agencies. Revista de Administração Pública, 49(6), 1375-1400.

Silva, M. B. (2012). Mecanismos de participação e atuação de grupos de interesse no processo regulatório brasileiro: o caso da Agência Nacional de Energia Elétrica (Aneel). Revista de Administração Pública, 46(4), 969-92.

Webster, J., \& Watson, R. T. (2002). Analyzing the Past to Prepare for the Future: Writing a Literature Review. MIS Quarterly, 26(2), xiii-xxiii.

Williamson, O. E. (1996). Corporate Finance and Corporate Governance. In: O. E. Williamson, The Mechanisms of Governance (pp. 171-194). New York: Oxford University Press. 